\title{
Sciendo
}

10.2478/topling-2019-0002

\section{But, you see, the problem is ... Perception verbs in courtroom talk: Focus on you see}

\author{
Magdalena Szczyrbak* \\ Jagiellonian University, Poland
}

\begin{abstract}
This article seeks to contribute to the body of research on the use of perception verbs in interaction and, more specifically, to enhance the understanding of how participants in courtroom proceedings exploit you see to manage the discourse as it unfolds and to negotiate stance. Against the background of earlier work on vision words in interaction, the study looks at parenthetical and non-parenthetical you see to reveal both perceptual and cognitive uses, and to identify their local pragmatic effect. As the analysis indicates, in the data at hand, lexical you see is more readily recruited than non-lexical you see, and it is found chiefly in grammatical and declarative questions. At the same time, it is the clause-initial you see that visibly brings out the epistemic tensions between the speakers and serves to contest the addressee's position. The study corroborates the claim that you see is an argumentative marker, whose meaning (and force) depends on its formal properties (position, complementation) and the relationship between the speakers.
\end{abstract}

\section{Key words}

comment clauses, courtroom talk, perception verbs, pragmatic markers, stance, you see

\section{Introduction}

Despite its wide recognition as a comment clause in contemporary English, parenthetical you see has attracted little attention as compared with I think, you know or I mean, whose pragmatics have been widely discussed across texts and contexts. This is all the more surprising given the commonness of you see and the role it plays in intersubjective positioning and the weighing up of, oftentimes, opposing stances. Several recent studies which discuss the interactional behaviour of you see talk about its perceptual, cognitive and evaluative meanings (Aijmer, 2004), describe its common parenthetical usage (Brinton, 2008) and point to its argumentative role in discourse (Ranger, 2010). None of them, however, focuses specifically on parenthetical you see in the legal context. The few studies that do recognize the importance of discourse markers like you see in courtroom examinations highlight their relevance to discourse control and the effect they have on the illocutionary force of the utterance (Hale, 1999; Innes, 2010). Still, there are no corpus-based studies focusing on the patterned co-occurrences of see with other discourse items, aiming to reveal the role of such patterns in negotiating speaker stance in contexts marked by power asymmetry. That is why this empirical work - taking a discourse-functional perspective - seeks to contribute to the study of you see in confrontational settings. It specifically aims to identify stance-related patterns with lexical and pragmatic you see as pursued by individual trial participants. The analysis considers the interplay between the properties of this clause (such as position

\footnotetext{
Address for correspondence: Magdalena Szczyrbak, Institute of English Studies, Faculty of Philology, Jagiellonian University, al. Mickiewicza 9a, 31-120 Kraków, Poland, E-mail: magdalena.szczyrbak@uj.edu.pl
} 
and complementation) and the relation between the interlocutors, i.e. their status in interaction. The study highlights the intersubjective nature of you see and, in line with Fitzmaurice (2004, p. 429), it views it as "the speaker's rhetorical construction of the interlocutor's perspective or attitude."

\section{Perception verbs in interaction: Focus on see}

Almost all languages have words describing perception and references to vision are no exception. In fact, vision appears to be the most dominant and talked about sense, with hearing ranking second (San Roque, et al., 2015, p. 46). More specifically, vision verbs have been found to be the most frequent forms among the perception terms used in everyday conversation, which shows, as San Roque, et al. (2015, p. 49) suggest, that vision-related references form a "common core" of human experience in perceptual language. Trying to explain the high frequency of vision words in interaction, the researchers (San Roque, et al., 2015, pp. 49-50) point to three possible factors, stressing that: 1) "language use reflects a pan-human preoccupation with visual experience" and that "vision often dominates our interpretation of sensory information"; 2) that there may simply be "more occasions to talk about visual objects than objects apprehended through the other senses" and, finally, that 3) "perceptual language reflects both sensory and social concerns" as it may be one of "the most readily and regularly shared perceptual experiences among interlocutors," with vision being treated "as the primary foundation for joint attention." One of the consequences of these conversationally embedded and socio-interactional factors is that perception verbs perform a range of pragmatic functions. These, as San Roque, et al. (2015, p. 50) maintain, include: "securing the attention of the addressee" (turn-initial listen), "establishing legitimacy of evidence in the face of an addressee's scepticism about a factual claim" (see?) and "redirecting a sequence of talk" (turn-initial look).

Elsewhere, seeking a motivated explanation for the link between vocabulary describing the (accessible) physical and social world and the (less accessible) world of reasoning and emotion, Sweetser (1990, p. 37) holds that there are major similarities between the general linguistic treatment of vision and intellect. She (Sweetser, 1990, p. 38) outlines a structure of perception metaphors in English, focusing on sight and hearing. In her view, the semantic extensions of sight include: "knowledge, mental vision," "control, monitoring," "physical manipulation, grasping" and "mental manipulation, control," all of which are linked to "the objective, intellectual side of our mental life" (Sweetser, 1990, p. 37). ${ }^{1}$ Following Sweetser (1990), Ibarretxe-Antuñano (2002) similarly holds that perception verbs are universally used to convey comprehension and knowledge, and she extends the list of metaphors in the perceptual domain, adding touch, smell and taste. The metaphors she enumerates for vision include: 'understanding is seeing', 'imagining is seeing', 'considering is seeing', 'finding out is seeing' and 'making sure is seeing', to name but some of them. Ibarretxe-Antuñano (2008, p. 28) considers sight as one of the ways of "experiencing and being in contact with the world" as well as "the perceptual modality for identifying and gathering more reliable information." She (Ibarretxe-Antuñano, 2008, p. 29) concludes, however, that since the semantic extensions of perception verbs, including sight verbs, result from our own conceptualization and experience of the world, the more specific 'understandingis-vision' association should be replaced by the more general 'understanding-is-perception' link.

Metaphorical uses aside, phrases with sight verbs such as I see or you see have also been found to operate as discourse markers which help speakers "to manage attention and intersubjective alignment in ongoing interaction" (San Roque, et al., 2018, p. 386). In the words of San Roque, et al. (2018, p. 376), such uses represent "an extension to a specialized interpersonal function" rather than a change in meaning typical of traditional polysemy. Like Sweetser (1990), San Roque, et al. (2018, p. 375) link cognition to the faculty of vision, pointing out that sight words are commonly found in reference to cognitive states and processes such as knowing, understanding or deducing, and that they enable speakers to negotiate immediate perceptual experience through language (San Roque, et al., 2018, p. $372)$. Discussing the role of sight verbs in interaction, San Roque, et al. (2018, p. 383) associate them also with meanings of "focused attention" (such as 'checking on' or 'looking after') and with

\footnotetext{
${ }^{1}$ Drawing parallels between vision and intellection, Sweetser (1990, p. 38) notes that the ability to consciously choose one stimulus from many is a characteristic of vision and of thought, unlike hearing which is "less consciously and readily focused than vision." Attending to one auditory stimulus may thus require more effort, which in turn explains why vision is the primary source of information about the world (Sweetser, 1990, p. 39).
} 
"expressions of socializing." ${ }^{2}$ Talking specifically about the role of sight verbs in regulating interaction as it unfolds, the researchers examine the sequential context of the interaction and its intersubjective dimension. This leads them to the conclusion that sight verbs play a significant role as directives and markers of attention. As for perception directives (usually imperatives), San Roque, et al. (2018, p. 384) note that they "typically attempt to direct an interlocutor's attention towards an object in the environment," or that they can give a warning or elicit an assessment. Thus, they say, such imperatives create both "triadic engagement," by redistributing epistemic access (with the recipient having a basis to know what the speaker knows) and a "stance triangle" (du Bois, 2007) in which the speaker's stances converge in intersubjective alignment (San Roque, et al., 2018, p. 385). They go even further and suggest that there is a close link between "jointly attending to objects in the environment" and "mutual appraisal of the conversation itself" (San Roque, 2018, p. 385).

The interactional behaviour of you see has also been examined in several other corpus-based studies, differentiating between its lexical use (with a direct object complement) and its discourse (or parenthetical) use (with no explicit complement). One such study uses an English-Swedish translation corpus to investigate the interface between perception, evidentiality and discourse particle use (Aijmer, 2004). Similarly to San Roque, et al. (2018), Aijmer too takes the notion of polysemy as the point of departure and approaches it from a cross-linguistic perspective. In her analysis of parallel corpus data, she examines the core meaning of see (i.e. 'seeing with one's eyes') and its extensions which, as she says, depend on the grammatical context including complementation patterns (Aijmer, 2004, p. 268). To demonstrate the effect of complementation on the interpretation of see, Aijmer (2004, p. 253) considers its perceptual, cognitive and evaluative meanings. In her description of discourse particle use of you see, in turn, Aijmer (2004, p. 264) observes that it is placed outside the utterance in the pre-front field or end-field, or parenthetically inside the proposition. She identifies two main roles of non-lexical you see: the connective function (textual level) and that of marking solidarity and politeness (interpersonal level).

Likewise, parenthetical uses of see are discussed in one of the chapters in Brinton's (2008) book on the comment clause in English, in which she admits that parenthetical see is less commonly explored than comment clauses with other verbs. Basing his observations on diachronic corpus data, Brinton (2008, p. 159) observes that you see has undergone a process of grammaticalization and that it instantiates metaphorization from the physical to the cognitive domain (i.e. from vision to mental 'vision'). Among the see-type comment clauses, Brinton enumerates you see, as you see, so you see and see, and she illustrates their use with evidence from several dialects. In her account, pragmatic you see serves primarily to claim the hearer's attention, and in particular to 1) negotiate with hearers their acceptance of the speaker's arguments (p. 159); 2) explain or justify the preceding utterance (p. 134), that is to signal the fact that "speakers recognize the hearers will need justification or explanation for the claims made" (p. 159); 3) mark negative politeness, by presupposing, raising, or asserting common ground, or by claiming mutual understanding when the speaker feels that his/her claim may provoke surprise or blame and thus constitute a face threat (pp. 159-160); 4) draw the hearer into the discourse and encourage him/her to follow the emotional trend of the discourse (p. 160) and, finally, to 5) jog the hearer's memory as to the necessary details, with the speaker not only presupposing but also asserting the hearer's knowledge (p. 160, cf. Brown and Levinson 1987 [1978]). When contrasting the pragmatic functions of you see with those of as you see, Brinton notes that the first of the two is a neutral marker which does not assert the truth value of the utterance (although, as she admits, it often co-occurs with the expression of speaker evaluation [2008, p. 159]) whereas the latter is "an affirmative marker which asserts the truth value of the utterance it accompanies" (Brinton, 2008, p. 160). She also likens as you see to as you can see, stressing that it is mostly literal and refers to something within the hearer's sight, just as its modal variant does (Brinton, 2008, p. 137).

Finally, in Ranger's (2010) enunciative analysis of you see, which is the last study to be discussed here, the clause is described as an argumentative marker which links propositions in an inferential relationship. In other words, as Ranger (2010, p. 127) puts it, the target of you see is not "the clause to

\footnotetext{
${ }^{2}$ San Roque, et al. (2018, p. 384) demonstrate recurrent semantic associations for sight verbs in English, including cognition, attention, socializing, locating and co-identity.
} 
which it is appended but rather the inferential relationship between this clause and a preceding proposition or, more precisely, representation." Like Brown and Levinson (1987 [1978]) and Brinton (2008), Ranger too acknowledges that you see is a politeness marker. In his view, however, the marker is not inherently polite or impolite; rather, as he suggests, its role depends on the interplay between its syntactic position and the relationship between the interlocutors (Ranger, 2010, p. 127) as well as these interlocutors' positioning towards the propositions (Ranger, 2010, p. 114). Ranger (2010, p. 124) also links you see to spoken contexts in which the speaker holds the floor and he validly observes that in confrontational encounters, explanatory you see in initial position highlights discontinuities between the speakers (Ranger, 2010, p. 127).

In light of the above findings, there are good reasons to suggest that you see and its patterned cooccurrences are an essential part of the intersubjective positioning strategies deployed by participants in courtroom proceedings (for an overview of descriptions of you see in various interactional contexts, see Appendix 1). With this in mind, in what follows, I present the most salient patterns with you see as found in trial data, focusing in particular on the parenthetical (or discourse particle) use of this clause and demonstrating its relevance to the interactional co-construction of stance.

\section{Findings and discussion}

\subsection{Data, method and research focus}

The data used in the analysis come from an English adversarial trial. ${ }^{3}$ The examinations pertain to historical evidence and the manner in which the claimant (acting as a litigant in person) misinterpreted it in his work related to WWII. During the trial, the participants put forward and defended mutually exclusive accounts of disputed actions and events, and they referred to evidentiary material including diaries, reports, photographs and blueprints. It is important to note that since this was a bench trial, i.e. one with no jury present, the speakers did not have to orient themselves to the non-participatory audience (which is the case in jury trials) and so their primary communicative goal was to win the judge's positive regard and to affect his final assessment. This translated into epistemic tensions between the opposing parties who negotiated their stances in front of the judge, relying on a variety of discursive strategies (see, e.g., Szczyrbak 2016; 2018a; 2018b). In the study, I looked at the transcripts documenting the trial to identify the most salient patterns with you see with a view to explaining their role in the stancetaking practices pursued by individual speakers. In doing so, I used the concord function of corpus analysis software (WordSmith Tools). Included in the analysis was also the modal variant of the clause, you can see. Following the automatic ordering of the concordances, I manually singled out the most visible patterns with parenthetical and non-parenthetical occurrences of you (can) see, as shown in Table 1.

For the purpose of the analysis, I took stance (taking) to mean a collaborative activity through which speakers evaluate objects, position subjects and align with other subjects ${ }^{4}$ (du Bois, 2007, p. 163). As suggested in this approach, through their stances, co-present speakers "assign value to objects of interest," "position social actors with respect to those objects," and "calibrate alignment" between themselves, thus invoking "systems of sociocultural value" (du Bois, 2007, p. 139). In agreement with this, as I too believe, stance is realised through varied interactional practices and linguistic resources which incorporate patterned co-occurrences of various discourse items. Against this background, the investigation aimed primarily to: 1) identify patterned co-occurrences with you see and their distribution per participant; 2) explain the role of parenthetical vs non-parenthetical you see in negotiating speaker stance; 3 ) identify literal vs non-literal meanings of you see and explain their role in negotiating speaker stance. Seen more broadly, the analysis sought to demonstrate the role of patterns with you (can) see in the intersubjective positioning of interactants in an institutional setting. Identification of such strategies,

\footnotetext{
${ }^{3}$ The trial took place in London in the year 2000 and the linguistic material analysed represents British English. The trial transcripts can be accessed at: https://www.hdot.org/trial-materials/trial-transcripts/.

${ }^{4}$ It should be noted that in this approach, alignment is not tantamount to agreement. Rather, as du Bois argues, this notion embraces both convergence and divergence, which, as he puts it, "are equally at home in the dialogic engagement of co-participants" (2007, p. 174). Defining the stance act as a set of three actions, i.e.: evaluation, positioning and alignment, du Bois views stance alignment as "a point along a continuous scale or range of values" which means that it can be "relatively positive or negative" (2007, p. 162). In this way, as he continues, an act of alignment "serves to calibrate the intersubjective relationship implicit in the stances of engaged co-participants" (du Bois, 2007, p. 162).
} 
it may be posited, reveals the power asymmetries between the speakers as well as helps to understand these speakers' identities as negotiated in the ongoing interaction (cf. Bucholtz and Hall, 2005). Also, the analysis was intended to shed more light on the organization of courtroom discourse and to show in line with Sinclair's (1987) idiom (collocational) principle - that speakers tend to choose co-occurring items rather than single units. The results of the investigation are reported below.

\subsection{Patterns with you see}

\subsubsection{Overview}

Following the semi-automated analysis, it was found that patterns with you (can) see were relatively frequent in the data and that both literal and non-literal meanings were active. It was also possible to see that non-parenthetical you see was preferred over parenthetical you see. Overall, you see was found in various interactional configurations (Table 1), some of which are discussed in detail in Sections 3.2.1 and 3.2.2 below.

\subsubsection{Parenthetical you see}

Of greatest interest in this study were parenthetical uses of you see and that is why they are addressed first. As it transpired, in this group, clause-initial you see was most salient, ranking as the second most frequent pattern of all the analysed (parenthetical and non-parenthetical) co-occurrences. On the other hand, both clause-medial and clause-final uses proved to be much less frequent. This corroborates Brinton's (2008: 135) results and points to the prevalence of clause-initial you see also in the courtroom context. $^{5}$

Clause-initial you see as found in the courtroom data was interesting for several reasons. Firstly, in line with Ranger's (2010) findings, it clearly was argumentative and it linked propositions in an inferential relationship, which, given the confrontational nature of courtroom examinations, brought out the discontinuities between the speakers (cf. Ranger, 2010, p. 127) rather than stressed commonalities (but cf., e.g., Aijmer, 2004, p. 264 on non-legal contexts). Added to this was the prefacing with but, which too marked contrast between competing stances. Secondly, in the data, you see also tended to cooccur with evaluative items, many of which signalled some kind of trouble and were linked to negative assessments. Thirdly, more often than not (44 out of 64 tokens), ${ }^{6}$ you see was followed by $I$, which, in turn, seemed to indicate that superior or "proclaimed knowledge" would follow (cf. McCarthy, 1994, p. 112 cited in Hale, 1999, p. 69). Less frequent, but also attested, were direct appeals to the addressee (mainly the claimant) such as you see, you and you see, Mr Irving, claiming the addressee's attention and contesting his arguments. All of this corroborates earlier findings on clause-initial you see and shows that in courtroom talk, it carries a strong pragmatic force. ${ }^{7}$

\footnotetext{
${ }^{5}$ Unlike, however, Stenström's (1995) data which revealed the highest frequency of sentence-final you see.

${ }^{6}$ Based on a corpus query with you see as the node and $I$ as the context word, with the search horizon set at $0 \mathrm{~L}$, $5 \mathrm{R}$.

${ }^{7}$ You see has been found to be pragmatically stronger than well (Hale, 1999, p. 70) and more argumentative than you know (Erman, 1987, pp. 117-118).
} 
Table 1. Patterns with you (can) see in the courtroom data

\begin{tabular}{|c|c|c|c|c|c|}
\hline \multirow{3}{*}{ PATTERN } & \multirow{2}{*}{ TOTAL } & \multicolumn{4}{|c|}{ PARTICIPANT } \\
\hline & & Judge & Claimant & Counsel & Witnesses \\
\hline & \multicolumn{5}{|c|}{ DECLARATIVES } \\
\hline YOU SEE + compl. & 65 & 1 & 14 & 19 & 31 \\
\hline (You see that + compl.) & (7) & 0 & (3) & (1) & (3) \\
\hline YOU CAN SEE + compl. & 58 & 3 & 26 & 12 & 17 \\
\hline (You can see that + compl.) & (12) & $(0)$ & (2) & (3) & (7) \\
\hline YOU SEE,$\ldots$ & 64 & 8 & 10 & 35 & 11 \\
\hline (But, you see, ...) & (14) & (3) & (3) & (8) & (0) \\
\hline \multicolumn{6}{|l|}{ [clause-initial] $^{8}$} \\
\hline .. YOU SEE ... & 19 & 4 & 3 & 10 & 2 \\
\hline \multicolumn{6}{|l|}{ [clause-medial] } \\
\hline$\ldots, Y O U$ SEE. & 10 & 2 & 2 & 5 & 1 \\
\hline \multicolumn{6}{|l|}{ [clause-final] } \\
\hline AND YOU SEE & 8 & 0 & 3 & 2 & 3 \\
\hline (and you see that + compl.) & (1) & $(0)$ & (1) & $(0)$ & $(0)$ \\
\hline AND YOU CAN SEE & 11 & 0 & 8 & 1 & 2 \\
\hline (and you can see that + compl.) & (2) & 0 & (1) & 0 & (1) \\
\hline AS YOU SEE & 7 & 1 & 0 & 2 & 4 \\
\hline AS YOU CAN SEE & 15 & 1 & 8 & 2 & 4 \\
\hline SO YOU SEE & 2 & 0 & 0 & 0 & 2 \\
\hline SO YOU CAN SEE & 4 & 0 & 0 & 1 & 3 \\
\hline IF YOU SEE & 16 & 3 & 6 & 2 & 5 \\
\hline (if you see what I mean) & (8) & (3) & (2) & (2) & (1) \\
\hline $\begin{array}{l}\text { WH-WORD + YOU SEE } \\
\text { [e.g. what you see] }\end{array}$ & 18 & 2 & 10 & 2 & 4 \\
\hline \multirow{2}{*}{$\begin{array}{l}\text { WH-WORD + YOU CAN SEE } \\
\text { [e.g. where you can see] }\end{array}$} & 4 & 0 & 1 & 2 & 1 \\
\hline & \multicolumn{5}{|c|}{ INTERROGATIVES } \\
\hline $\begin{array}{l}\text { YOU SEE ...? } \\
\text { [declarative question] }\end{array}$ & 14 & 0 & 2 & 12 & 0 \\
\hline$\ldots, Y O U$ SEE? & 1 & 0 & 0 & 1 & 0 \\
\hline CAN YOU SEE...? & 20 & 0 & 19 & 1 & 0 \\
\hline COULD YOU SEE...? & 2 & 0 & 1 & 0 & 1 \\
\hline DO YOU SEE...? & 77 & 2 & 15 & 58 & 2 \\
\hline (Do you see that?) & (24) & $(0)$ & (2) & (22) & (0) \\
\hline DID YOU SEE...? & 14 & 0 & 14 & 0 & 0 \\
\hline
\end{tabular}

The above-mentioned clause-initial uses of you see are exemplified by excerpts (1), (2) and (3). In the first of them, the counsel demonstrates his confidence, if not dominance, claiming that he does not need to prove anything to the opponent whose position he describes as a "slightly bizarre suggestion." Other examples with the same you see + I pattern, similarly, manifest the speaker's negative attitude (e.g. you see, I have a problem; you see, I am anxious) or strong conviction (e.g. you see, what I am saying in this; you see, I am a bit persistent on this).

\footnotetext{
${ }^{8}$ Clause-initial and -final occurrences of you see include only these instances which were separated with commas since in the absence of prosodic marking, it was not possible to establish their parenthetical status otherwise. Clause-medial occurrences of you see, in turn, include both the instances with commas and without commas (their parenthetical status was clear).
} 
(1) [Counsel] So why would it need a gas type door with a peep hole with double eight millimetre thick glass and a metal grill on it?

[Claimant] Well, I think you will have to show us the evidence for this.

[Counsel] I will do.

[Claimant] And the evidence that this door was intended for that particular room and the evidence it was possible to obtain doors without the peep holes and the evidence that the room was not intended to be used for other purposes too.

[Counsel] No, Mr Irving. You see, I do not have to prove anything. I am testing your, I have to say, slightly bizarre suggestion that you put Zyklon B into a room where the people are already dead. You tell me, "Oh, well, that is because they wanted to delouse the corpses". Then I asked you, "Why then does it need a gas type door with a peep hole and a metal protection on it?"

On the other hand, the you see + you cluster was identified both in the counsel's and the judge's turns. Although, by analogy to you see $+I$, the pattern reflected the speaker's critical stance, as in (2), it seemed less useful for presenting his preferred argument or "proclaimed knowledge" and this may explain why it was less willingly deployed than the $I$-oriented pattern.

(2) [Counsel] That is another problem with the document. You would have expected it to say diese Juden frager [sic!]? ${ }^{9}$

[Claimant] Of this Jewish problem, but it does not, of course.

[Counsel] I quite agree.

[Claimant] So that does not help you very much.

[Counsel] I am not looking for help, Mr Irving. You see, you have completely the wrong end of the stick.

[Claimant] I am trying to help you because I am enjoying this.

Another interesting co-selection which emerged was that with the contrastive marker but, boosting the argumentative orientation of you see. One such use is illustrated by (3), where, again, you see is followed by the speaker's negative assessment (your omissions) and becomes even more confrontational since it is used in a declarative question. In fact, the use of you see in declaratory questions turned out to be a recurrent pattern in the counsel's speech, as illustrated by (10), (14) and (15).

(3) [Claimant] (...) I mean, if I am an author of a book which has not got to be a two volume book, writing a book that is going to come down to a reasonable economic length, you have to make judgment calls on what you put in and what you take out. If something you are going to leave out does not really advance the argument one way or the other, then you leave it out.

[Counsel] But, you see, your omissions of the Goebbels' references to Hitler are the omissions of all those references which put Hitler in a bad light?

[Claimant] Let me also put something in a legal sense. This entry can be held against Goebbels' evidence but not against Hitler, of course.

[Counsel] We are not conducting a legal enquiry when we are writing a history book, Mr Irving, are we?

Turning now to clause-medial occurrences of you see, the first thing to note is that they appeared less commonly than did the clause-initial ones. As the examples show, this form was backward-looking, marking transitions between the arguments (cf. Erman, 1987, p. 117) and, at the same time, ensuring textual connectivity (cf. Aijmer, 2004, p. 264). This marker had an explanatory function, which is the reason why it was sometimes followed by so or because, as in (4). Clearly, clause-medial you see was not as confrontational as the clause-initial variant and its presence in the data can be described as marginal.

\footnotetext{
${ }^{9}$ This is probably a misspelt version of the German Judenfrage ("Jewish question").
} 
(4) [Counsel] This is all what I call intentional material. If the average corpse, balancing between young children and fat men, if you like, is, say, 60 kilograms, yes?

[Expert witness] Yes.

[Counsel] Is that fair? I do not think in kilogrammes, you see, so I have to have your help.

[Expert witness] Yes.

[Counsel] 60 kilograms, then the capacity for each hoist, each journey, would be about 25 corpses, would it not?

[Expert witness] Yes.

Even less frequent, clause-final you see was too backward-looking and so it had the preceding clause within its scope, as shown in (5). Its goal was to justify the speaker's claim and to make it relevant to the ongoing discourse. It is also interesting to note that there was merely one instance in which turnfinal you see was a question tag seeking a confirmatory response from the addressee. Despite its infrequency, for illustrative purposes, it is shown in (6).

(5) [Judge] I think I am entitled therefore to look at the totality of all this.

[Claimant] Well I would have preferred that they would have marked those passages in the full text of the speeches.

[Counsel] They are.

[Judge] They are. That is what has been done, you see. I have the full context.

(6) [Expert witness] (...) First, do you see the coke supplies at Auschwitz as being significant? [Claimant] Coke?

[Judge] "Coke" did you say?

[Counsel] Coke, C-O-K-E, which in those days meant what it said!

[Judge] I think I assumed that.

[Counsel] You are going to raise that with Professor - I need to know because he has to prepare himself, you see?

[Claimant] Yes.

Quite similarly, in all but one case, if you see what I mean occurred sentence-finally, either in declaratory or interrogative form, serving as an explanation for the preceding utterance and signalling the speaker's need to justify his claim (cf. Brinton, 2008, p. 159). Here, in agreement with Aijmer (2004, p. 262), the $w$ h-complement can be seen as a 'metalinguistic reference' to the preceding proposition rather than an 'ordinary reference' to an object.

(7) [Claimant] I think what he is saying is that nothing was to be seen when they inspected on site. [Counsel] That may be.

[Judge] What is a gas fitted door.

[Counsel] It is a door which has seals so that air cannot come in and gas cannot come out, if you see what I mean.

As regards observations on the recruitment of as you see in the data, they are consistent with Brinton's (2008) findings. The data showed that as you see was indeed "an affirmative marker" asserting the truth value of the utterance (Brinton, 2008, p. 160) and that its meanings were primarily literal (similarly to as you can see). What is more, the presence of spatial deictic markers indicated that the speaker was referring to something that was within the addressee's sight, as in the excerpt shown in (8).

(8) [Expert witness] Yes. That is a collection of documents. Actually I issued this in 1990 when this was actually called, as you see here, documents about the question of German unity so that, when the book came out, the question was solved.

In sum, the findings regarding parenthetical you see are in agreement with earlier studies showing a link between vision and cognition as well as the use of vision verbs as discourse markers which help 
speakers to manage attention and to perform actions "that seek to attain or maintain alignment between interlocutors" (San Roque, et al., 2018, p. 385).

\subsubsection{Non-parenthetical you see}

Although the focus of the current study is on parenthetical you see, as described above, the discussion of the varied senses and functions of the verb see, and their relevance to stancetaking, would not be complete were non-parenthetical uses to be excluded. Therefore, in what follows, I describe several interactional configurations with lexical you see, which, as it transpired, were more common than their non-lexical counterparts. Worthy of note is also the fact while parenthetical you see was predominantly non-literal, non-parenthetical you see carried both literal and non-literal meanings.

Given the subject matter of the trial, i.e. the disputed misrepresentation of WWII-related historical evidence, a great share of the questioning involved a detailed analysis of visual material as well as written documents. This does not come as a surprise then that you see principally had the literal, perceptual meaning, drawing the addressee's attention to tangible referents, e.g. specific parts of documents, as in (9). Non-literal you see, on the other hand, was found in various syntactic configurations (e.g. you see what; you see there is; you see how) and pointed to 'mental vision,' as in (10).

(9) [Expert witness] No, he did not - there was a basket in there, and I do not know if you want to go into the reason.

[Claimant] No, not really. I am just looking at dimensions now. You see where it says on the right-hand side "240 centimetres from floor to ceiling"; that was the height of this mortuary, was it not?

[Expert witness] Yes.

(10) [Claimant] Yes, this is Dr Goebbels.

[Counsel] It may be?

[Claimant] I am sorry it is, because it is not in the subjunctive. If it is not in reported speech. If he was reporting what Hitler had said, it would be not "hat" but "ete", [sic! ${ }^{10}$ that is the way reported speech is done in German.

[Counsel] You see no ground for thinking that Hitler said anything like this?

[Claimant] This is Dr. Goebbels' gloss on what Hitler had said.

[Counsel] You think it is just a gloss on what Hitler said. Do you think it is a [sic!] invention?

[Claimant] That is what the language tells us Mr Rampton it is not in subjunctive, so it is not him reporting what somebody else said.

It was also noted, in line with earlier studies (cf., e.g., Stenström, 1995), that the thatcomplementation of you see was rare. Unlike Aijmer's (2004, p. 268) observation, however, you see that generally did not refer to 'seeing' as the source of knowledge. In fact, there was only one example, in which you see that could be paraphrased as you know that, with all the other occurrences being related to perception and attending to objects which were within the addressee's sight, as in (11).

(11) [Expert witness] Yes. The space we talked about, the counterweights [Claimant] It is not an extra space at all. It is just part of the actual shaft?

[Expert witness] Yes. You see that there is some space left so that the weight can go there.

[Claimant] We gained the impression two days ago that there was a separate channel for the counterweight to go down?

By contrast, you can see turned out to be the fourth most frequent pattern (58 tokens). Such a high frequency of can can be justified by the fact that in the case of stative verbs like see, it functions like a progressive form expressing duration (Aijmer, 2004, p. 258). It may also be argued after Aijmer (2004, p. 259), drawing on Panther and Thornburg (1999, p. 339), that can conveys the implication of actuality or truth and, further, that "ability stands metonymically for the actual process (the cognitive principle

\footnotetext{
${ }^{10}$ This is probably a misspelt version of the German hätte.
} 
'actuality over potentiality') with verbs of perception and mental process verbs." This means that 'the ability to see' equals the actual perceiving, as in (12).

(12) [Claimant] Very well. The last picture that I wish to show the court and the witness and ask a question on is this large picture. This is crematorium number 2. You can see the scale of it from the people standing down there, the tourists who arrived up that path, and this is Leichenkeller number 1 , morgue number 1 , on which we have now zeroed in, in other words.

[Expert witness] Yes.

As the data bore out, you see marked a strong presence in questions, directing the addressee's attention to discourse objects and subjects or to objects in the physical environment (photographs or documents). The prevalence of interrogatives with you see, on the one hand, confirms the intersubjective dimension of courtroom talk (and the 'negotiability' of stance) and on the other, it supports the claim that vision is the most common basis for joint attention (cf. San Roque, et al., 2015, p. 50). As expected, most of the questions concerned the ongoing argumentation (as in [13]) or objects in the here-and-now physical setting (as in [14] and [15]), rather than past referents.

(13) [Counsel] (...) Do you see any resonance or similarity between what Mr Irving there said and what he said in the middle of page 69 of your report?

[Expert witness] Oh, yes. It is a kind of attacking what he calls a legend, or what he may call also a lie, that became a religion, so-called religion, of millions of honest people. So it is a kind of way of thinking that because he says the essence of the Holocaust is a lie, and the people do not believe that it is a lie, but it is the truth, this truth is a religion.

(14) [Counsel] You see the letter of 28th June 1943?

[Expert witness] Yes.

[Counsel] With Jahrling's name at the bottom in handwriting, do you see that?

[Expert witness] Yes.

(15) [Counsel] We have read what you wrote as being the translation of the table talk in that paragraph. You see it is footnoted 16?

[Claimant] Yes.

[Counsel] Now please turn to page 643.

More precisely, it was noted that grammatical questions in the present tense (do you see ...?; do you see that?; can you see...?) were found chiefly in the counsel's turns. In fact, a significant difference was revealed between the questioning strategies pursued by the counsel, an experienced jurist, and the litigant, who represented himself. While the counsel favoured the present tense forms do you see...? and you see...? (without asking a single question with you see in the past tense), the claimant more readily recruited the modal variant can you see...? alongside do you see...? and backward-looking did you see...?, all of which were less frequent than the counsel's questions. ${ }^{11}$

That said, it needs to be added that question design was closely linked to the speaker's epistemic stance and the intended pragmatic effect. From this angle, it is worth remembering that both polar interrogatives (do/can you see...?) and declarative questions (you see....?) seek confirmation rather than

\footnotetext{
${ }^{11}$ This difference may be put down to several factors; however, there are good reasons to believe that the litigant's lack of legal training and knowledge of court procedures was one of them.
} 
information. ${ }^{12}$ This seemed to be reflected in the data since do you see...? (53 tokens) $)^{13}$ yielded 26 confirmatory responses, 18 ambiguous ones and only 9 disconfirmations. In the case of can you see..? (19 tokens), asked mainly by the claimant, only half the responses were straightforward yes answers. However, a caveat should be added here. As it turned out on closer inspection, several examples containing the clusters can you see and do you see were effectively open questions which did not expect a yes or no answer (as in can you see any reason why; can you see who and what on earth connection do you see; what difference do you see). This shows that caution is needed in an analysis of corpus data and that sweeping generalizations should be avoided. Last but not least, turn-final do you see that? (24 tokens) was generally followed by confirmatory responses (22 tokens), most of which (14 tokens) were produced by the witnesses in response to the counsel's questions (as in [14]). ${ }^{14}$

As regards declarative questions, Bongelli, et al. (2018, p. 41) suggest that they be explicated as: "I tell you that I am almost certain that $p$. I strongly suppose that $p$, but I am not completely sure, therefore I ask you for confirmation." Thus, they argue (Bongelli, et al., 2018, p. 41), declarative questions represent the uncertain epistemic position; however, the degree of uncertainty is low, with the speaker projecting the "believing" epistemic stance. This agrees with the claim that through declarative questions, the speaker "merely seeks to reconfirm or alternatively to convey inferences, assumptions, or other kinds of 'best guesses"' (Heritage, 2010, pp. $48-49$ cited in Bongelli, et al., 2018, p. 41). In the data at hand, rather unsurprisingly, all but two of the declarative questions with you see were produced by the counsel.

Finally, from a broader perspective, it may be argued that all of the questions with you see aimed to redistribute epistemic access and to attribute a particular perspective to the hearer (cf. Fitzmaurice, 2004, p. 431), thus collaboratively co-constructing stance.

\section{Conclusions}

In this paper I have sought to enhance the understanding of how participants in courtroom examinations exploit the "discourse" extensions of the perception verb see to manage the interaction as it unfolds and to calibrate their intersubjective relationship - that is to negotiate stance. Against the background of prior work in this area, I have demonstrated the link between 'vision' and 'knowing and understanding' and pointed to the fact that as in ordinary conversation, also in institutional contexts, speakers frequently negotiate their perceptual experience with the use of one of the most common English verbs, i.e. see.

As noted previously, the link between vision and cognition was borne out by the courtroom data which revealed that you see was used as "the foundation for joint attention" and to direct the addressee's attention towards physical or discourse objects and subjects. While both perceptual and cognitive meanings were present, pragmatic you see, which was the main focus of the study, proved to be less frequent than lexical uses. Notwithstanding the above, clause-initial parentheticals with you see formed a salient pattern (the second most common choice in the data) associated with the speaker's attempt to challenge opposing stances and to establish legitimacy for his own position. In addition, the you see $+I$

\footnotetext{
12 At this point, a clarification is however needed. As reported by Bongelli, et al. (2018, p. 37), two different positions can be found in the literature, according to which polar interrogatives are open to two different readings. In Bolinger's view (1978 in Bongelli, et al., 2018, p. 37), polar interrogatives (e.g. Is it still snowing outside?) are not neutral questions awaiting a yes or no response, but rather confirmation-seeking questions since the preferred reading (here: it is still snowing) "being lexicalized, is assigned more probability to be true than the negative" (Bongelli, et al., 2018, p. 37). Coleman (1974 in Bongelli, et al., 2018, p. 37), on the other hand, argues that polar interrogatives are neutral in their design and that they perform the social action of information seeking, which means that both yes and no are equally expected (e.g. it is still snowing or it is not snowing anymore). Against this background, Bongelli, et al. (2018, p. 37) posit that only prosody, turn-sequential position and propositional content can help to establish whether a given polar interrogative is information- or confirmation-seeking (and hence neutral or non-neutral). In the data analysed in this study, there was no prosodic marking; however, given the communicative goals of the questioner (the counsel or the litigant), the polar interrogatives were in all probability confirmation-seeking ones, with the speaker trying to "assign more probability" to the propositions contained in the questions.

13 This figure excludes turn-final do you see that?

${ }^{14}$ For a fuller understanding of the pragmatic effect of different types of questions and responses, a more detailed analysis would be needed, involving individual trial phases (examination-in-chief vs cross-examination) and looking at various speaker configurations. This, however, falls outside the scope of the current study.
} 
pattern (subsumed by clause-initial you see) preceded negative assessments and was also recruited to stress epistemic divergencies between the speakers. This stands in contrast with polite or facilitative uses identified elsewhere, but substantiates the claim that in confrontational contexts, you see in initial position "highlights discontinuities between the speakers" (Ranger, 2010, p. 127). On the other hand, both clause-medial and clause-final occurrences of pragmatic you see appeared to be more textual than interpersonal, which may explain why they were rather infrequent. With regard to lexical uses of you see, do you see...? and you see + complement ${ }^{15}$ emerged as the two most frequent choices. The interrogatives do you see...? made confirmation or disconfirmation relevant to the ongoing discourse and by using them, the questioner (mostly the counsel) showed strong epistemic commitment to the propositions concerned. Equally interesting, although less frequent, were declaratory questions (also preferred by the counsel) which, similarly, projected low certainty and thus implied nearly equal epistemic footing between the speakers.

That being said, I hope to have provided more insight into how you see is used in interaction, focusing specifically on its behaviour in a competitive courtroom environment and the role it plays in the rhetorical construction of intersubjective stance. Still, to paint a fuller picture, more analyses are needed, demonstrating how other markers with see (e.g. I see or imperative see) are used to manage discourse and the participants' attention, and to negotiate subjective meanings in institutional contexts.

\section{References}

Aijmer, K., 2004. The interface between perception, evidentiality and discourse particle use - using a translation corpus to study the polysemy of see. TRADTERM - Journal of the Interdepartmental Centre for Translation and Terminology of the FFLCH/USP, vol. 10, pp. 249-277.

Algeo, J., 2006. British or American English? A handbook of word and grammar patterns. (Studies in English Language). Cambridge: Cambridge University Press.

Blakemore, D., 1987. Semantic constraints on relevance. Oxford: Blackwell.

du Bois, J.W., 2007. The stance triangle. In: R. Englebretson, ed. Stancetaking in discourse: Subjectivity, evaluation, interaction. Amsterdam and Philadelphia: John Benjamins, pp. 139-182.

Bolinger, D., 1978. Yes-no questions are not alternative questions. In: H. Hiz, ed. Questions. Dordrecht: Reidel Publishing Company, pp. 87-105.

Bongelli, R., Riccioni, I., Vincze, L. and Zuczkowski, A., 2018. Questions and epistemic stance: Some examples from Italian conversations. Ampersand, vol. 5, pp. 29-44.

Brinton, L., 2008. The comment clause in English. Syntactic origins and pragmatic development. Cambridge: Cambridge University Press.

Brown, P. and Levinson, S., 1987 [1978]. Politeness: Some universals in language usage. Cambridge: Cambridge University Press.

Bucholtz, M. and Hall, K., 2005. Identity and interaction: A sociocultural linguistic approach. Discourse Studies, vol. 7, no. 4-5, pp. 585-614.

Coleman, H.O., 1974. Intonation and emphasis. Miscellanea Phonetica, vol. 1, pp. 11-22.

Erman, B., 1987. Pragmatic expressions in English: A study of you know, you see and I mean in faceto-face conversation. Stockholm: Almqvist \& Wiksell International.

Fitzmaurice, S., 2004. Subjectivity, intersubjectivity and the historical construction of interlocutor stance: From stance markers to discourse markers. Discourse Studies, vol. 6, no. 4, pp. 427-448.

Hale, S., 1999. Interpreters' treatment of discourse markers in courtroom questions. Forensic Linguistics, vol. 6, no. 1, pp. 57-82.

Heritage, J., 2010. Questioning in medicine. In: A. Freed and S. Ehrlich, eds. "Why do you ask?": The function of questions in institutional discourse. New York: Oxford University Press, pp. 42-68.

Ibarretxe-Antuñano, I., 2002. MIND-AS-BODY as a cross-linguistic conceptual metaphor. Miscelánea. A Journal of English and American Studies, vol. 25, pp. 93-119.

Ibarretxe-Antuñano, I., 2008. Vision metaphors for the intellect: Are they really cross-linguistic? Atlantis. Journal of the Spanish Association of Anglo-American Studies, vol. 30, no. 1, pp. 15-33.

Innes, B., 2010. "Well, that's why I asked the question sir": Well as a discourse marker in court. Language in Society, vol. 39, pp. 95-117.

\footnotetext{
${ }^{15}$ You can see + complement was only slightly less frequent.
} 
McCarthy, M., 1994. What should we teach about the spoken language? Australian Review of Applied Linguistics, vol. 17, no. 2, pp. 104-120.

Panther, K-U. and Thornburg, L., 1999. The potentiality for actuality metonymy in English and Hungarian. In: K-U. Panther and G. Radden, eds. Metonymy in language and thought. Amsterdam and Philadelphia: John Benjamins, pp. 333-357.

Quirk, R., Greenbaum, S., Leech, G. and Svartvik, J., 1985. A comprehensive grammar of the English language. London: Longman.

Ranger, R., 2010. You see! Lexis. Journal in English Lexicology. Theoretical Approaches to Linguistic (Im)politeness, HS2, pp. 111-130.

San Roque, L., Kendrick, K.H., Norcliffe, E., Brown, P., Defina, R., Dingemanse, M., Dirksmeyer, T., Enfield, NJ., Floyd, S., Hammond, J., Rossi, G., Tufvesson, S., van Putten, S. and Majid, A., 2015. Vision verbs dominate in conversation across cultures, but the ranking of non-visual verbs varies. Cognitive Linguistics, vol. 26, no. 1, pp. 31-60.

San Roque, L., Kendrick, K.H., Norcliffe, E., and Majid, A., 2018. Universal meaning extensions of perception verbs are grounded in interaction. Cognitive Linguistics, vol. 29, no. 3, pp. 371-406.

Scheibman, J., 2002. Point of view and grammar. Structural patterns of subjectivity in American English conversation. Amsterdam and Philadelphia: John Benjamins.

Scott, M., 2012. WordSmith Tools (version 6), Stroud: Lexical Analysis Software.

Sinclair, J., 1987. Collocation: A progress report. In: R. Steele and T. Threadgold, eds. Language topics: Essays in honour of Michael Halliday. Amsterdam: John Benjamins, pp. 319-331.

Stenström, A-B., 1995. Some remarks on comment clauses. In: B. Aarts and Ch.F. Meyer, eds. The verb in contemporary English. Cambridge: Cambridge University Press, pp. 290-302.

Sweetser, E., 1990. From etymology to pragmatics. Metaphorical and cultural aspects of semantic structure. Cambridge: Cambridge University Press.

Szczyrbak, M., 2016. Say and stancetaking in courtroom talk: A corpus-assisted study. Corpora, vol. 11, no. 2, pp. 143-168.

Szczyrbak, M., 2018a. Diminutivity and evaluation in courtroom interaction: Patterns with little (Part 1). Studia Linguistica Universitatis Iagellonicae Cracoviensis, no. 135, pp. 59-68.

Szczyrbak, M., 2018b. Diminutivity and evaluation in courtroom interaction: Patterns with little (Part 2). Studia Linguistica Universitatis Iagellonicae Cracoviensis, no. 135, pp. 69-79. 
Appendix 1. Description of you see in selected sources ${ }^{16}$

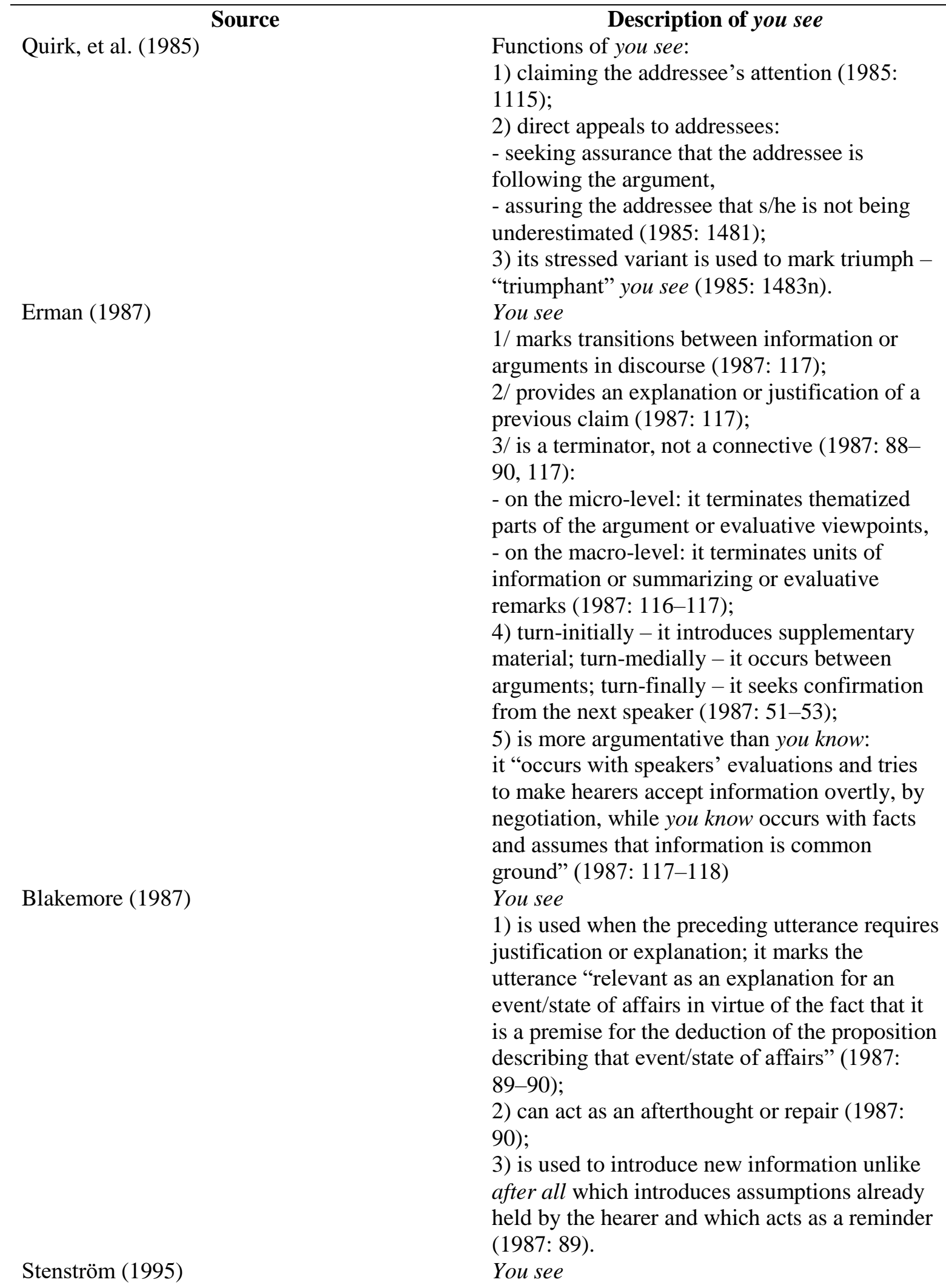

\footnotetext{
${ }^{16}$ The appendix details Brinton's (2008) findings including the sources reported therein (Brinton, 2008, pp. 133139) as well as lists Aijmer (2004) and Ranger (2010).
} 
Scheibman (2002)

Fitzmaurice (2004)

Aijmer (2004)

Algeo (2006)

Brinton (2008)
1) marks transitions between arguments in discourse (1995: 294);

2 ) is generally sentence-final, faces backward and has the entire preceding clause within its scope (1995: 298);

3) forms a separate tone unit (60\% of the time) and is very rarely followed by a that nominal clause.

You see

1) is a generic expression with first-person meaning, the speaker is projecting or universalizing his/her experiences (2002: 98); 2) co-occurs with modal auxiliaries (you can see) (2002: 96, 98, 117n).

You see

1) is a marker of intersubjectivity (like, e.g., you know and you say); it represents the "speaker's rhetorical construction of the interlocutor's perspective or attitude" (2004: 429); it attributes a particular perspective to the hearer (2004: 431);

2) can often be paraphrased as "I'm sure you understand that."

Discourse particle use of you see:

1) it does not belong to the proposition/it is placed outside the utterance in the pre-front field or end-field, or parenthetically inside the proposition;

2) on the textual level it has a connective function;

3 ) on the interpersonal level it is a solidarity and politeness marker (2004: 264).

You see is typical of British English; in American English in similar contexts you know is preferred (2006: 213).

You see

1) has undergone the process of grammaticalization; it exemplifies a shift from referential to non-referential (pragmatic) meaning (2008: 159);

2) instantiates metaphorization from the physical to the cognitive domain (from physical sight/vision to knowledge/mental 'vision') (2008: 159);

3) claims the hearer's attention;

4 ) is used by speakers to negotiate with hearers to accept their arguments (2008: 159);

5 ) serves as an explanation or justification for the preceding utterance (2008: 134); it "signals the fact the speakers recognize the hearers will need justification or explanation for the claims made" (2008: 159);

6) used for purposes of negative politeness: presupposing, raising, or asserting common ground (2008: 160); “[w]when the speaker 
Ranger (2010)

realizes that an utterance might provoke surprise or blame (i.e. be a face-threatening act), he or she may use you see to claim mutual understanding and thus avoid the face threat" (2008: 159);

7) marks a point-of-view "flip"; draws the hearer into the discourse; encourages the hearer to follow the emotional trend of the discourse; jogs the hearer's memory as to the necessary details; the speaker not only presupposes but also asserts the hearer's knowledge; the speaker and the hearer are collaborators (2008: 160 drawing on Brown and Levinson (1987 [1978]: 120, 124, 125);

8 ) is a neutral marker (it does not assert truth value) (2008: 160) but it often co-occurs with the expression of speaker evaluation (2008: 159);

9) has a triumphant usage (= "I told you so") (2008: 160);

10) used mainly sentence-initially (2008: 135);

11 ) is less frequent in varieties of North American English (2008: 134-135);

12) parenthetical use of the modal variant (you can see) rare in the BNC (2008: 134).

As you see

1) is a marker of intersubjectivity;

2) claims the hearer's attention;

3 ) is "an affirmative marker which asserts the truth value of the utterance it accompanies" (2008: 160);

4) is primarily literal and refers to something within the addressee's sight (similarly to as you can see) (2008: 137); it differs from resultative so you see which is more often figurative and which means "as you may conclude [from the preceding discourse]" (2008: 138).

You see

1) is a discourse marker but should not be regarded as an "unanalyable whole" (2010: 129);

2) is an argumentative discourse marker which links propositions in an inferential relationship (2010: 114);

3) the target of you see is not "the clause to which it is appended but rather the inferential relationship between this clause and a preceding proposition or, more precisely, representation" (2010: 127);

4) its role as a politeness marker depends on the interplay between its properties and contextual factors (e.g. how the speaker positions him/herself towards the co-speakers and the propositions) (2010: 114); 
5 ) is not inherently polite or impolite (2010:

114); whether it is a positive or negative politeness marker depends on its position and the relationship between the interlocutors (2010: 127);

6) is found predominantly in spoken English, including sermons, unscripted speeches, conversation and oral history (narrative), in the case of which the speaker holds the floor (2010: 124);

7) in narrative contexts, it is a marker of interaction (2010: 124);

8 ) in confrontational contexts, explanatory you see in initial position highlights discontinuities between the speakers (2010: 127);

9) in the classroom context, initial you see may be facilitative and it may encourage co-speaker participation (2010: 127). 